\title{
EL TANGO: TEMAS Y MOTIVOS
}

\section{Introducción}

Si preguntaramos en general, en el mundo, qué es el tango, obtendríamos como respuesta que el tango es una danza y música, que el tango es un baile específico del Río de la Plata. Aunque verdad, el tango no solo está compuesto de estas dos componentes, sino también de letras que, mundialmente hablando, quedaron no difundidas con respecto a las otros dos elementos del tango. Las letras de tango son reflejo de una realidad, de un ambiente y, podríamos decir también, de un pasado que quedó testimoniado en ellas.

En la investigación de las letras de tango nos encontramos con dos grandes "problemas". El primero de índole particular con respecto al tema elegido en este trabajo que se encuentra en la diferenciación de los temas y los motivos de las letras de tango, puesto que unos y otros aparecen en distintas letras de modos diferentes; el segundo es la manera de afrontar las letras de tango de acuerdo a una perspectiva histórico-social, lingüistica o literaria. Desde un punto histórico-social las letras de tango muestran un ambiente especifico (el ambiente del tango, del arrabal y sus personajes), a veces también hechos históricos (como ser los tangos de crítica social o de la inmigración), pero más que nada y sobre todo, muestran al hombre, sus sentimientos y su modo de pensar. Lingüísticamente el tango es interesante por el lenguaje que se utiliza: el lunfardo da más realismo y un signo típicamente rioplatense al tango. Pero en cuanto a las perspectivas, la literaria puede ser tan amplia y generosa que nos permite no sólo tratar el lunfardo como un elemento interno de las letras de tango, sino también los temas y motivos, y entre ellos, además aquellos de la realidad directa, histórica o social.

Los temas y motivos son una característica más de las letras de tango, una característica interesante y diversa. Su análisis nos muestra no sólo una realidad, limitada o no, sino también los valores morales de un pueblo, su modo de sentir, sus mitos de acuerdo a personas y personajes, sus preocupaciones individuales que a veces rompen los limites de un pueblo y son posibles en escala mundial.

\section{El origen y la evolución}

Para comprender los temas y motivos de las letras de tango es necesario comenzar con su discutido origen, su historia de contradicciones y sus etapas de desarrollo. Es posible que primero surgió la danza y luego la música que la acompañó, lo cierto es que la música y la danza fueron anteriores a las letras.

1 Danza que bailaban los negros a mediados del siglo XIX. Sus características principales son el ritmo y los quiebros del cuerpo. No se baila en parejas. 
Ya el origen de la palabra tango nos muestra una serie de definiciones discutibles, entre las cuales la más difundida es la que sostiene que tango (o tan-gó) se llamaba a los tambores cuyo compás dictaba el baile de los negros de Buenos Aires hacia finales del siglo XIX. Tango se llamaba a este instrumento de percusión, a la danza o al bailarin de ascendencia africana.

El origen del género musical tampoco es definitivo. Parece ser que indudablemente el origen es africano. Los negros de Buenos Aires se reunían en sociedades donde bailaban el candombe $^{1}$, las que frecuentaron los compadritos. Los compadritos como burla, comienzan a imitar el baile del candombe, sus quiebros de cuerpo y su coreografia. Asi se origina lo que llamaron primeramente milonga, que poseía la estructura musical y el modo de bailar de los bailes convencionales con el ritmo y la coreografia del candombe.

Pero es más seguro si se trata de buscar el origen en los tres géneros musicales que convivían en la época en el Río de la Plata: la habanera cubana, la milonga y el tango andaluz (de origen afro-cubano $)^{2}$. Estos tres géneros musicales tenian la misma base rítmica de la contradanza, que se difundió desde la Antillas hasta el Río de la Plata durante el siglo XIX. Es posible que sus nombres se confundieran entre sí y se llamara a una con el nombre de otra, por ello es muy difícil hablar de este tango como del tango que conocemos hoy (el tango como se lo conoce en la actualidad aparece en la década de 1890).

Primeramente los compositores y músicos no poseían formación musical, por eso se los llama "orejeros". Los músicos formaban dúos o tríos ambulantes que tocaban la flauta, la guitarrra y el violín; con el tiempo se agregaron el organito, el piano y el bandoneón (este último quedó como símbolo del tango).

En cuanto al origen es interesante el dato de que la danza fue primeramente bailada por hombres, dato paradójico, puesto a que el ambiente del tango semánticamente se relaciona con un ambiente "de machos". Los compadritos lo bailaron despreocupadamente imitando el baile de los negros. La danza fue en un principio repudiada, se la relacionó con el acto sexual por sus figuras de baile, pero su característica obscena se fue olvidando lentamente (tal vez luego de su éxito en París y en Europa en general en la primera década del siglo XX), así se fue difundiendo más allá de los límites del conventillo o el prostíbulo, entrando en los salones de baile y en las casas de familia. Existía un tango liso más difundido y otro con quebradas y cortes que fue criticado, lo cierto es que con el tiempo la danza fue estilizando su coreografia hasta llegar al tango actual.

\section{Las letras de tango}

\subsection{De las letrillas a las letras}

No es claro tampoco el lugar de nacimiento del tango como lo conocemos hoy. Algunos se inclinan a la teoría de que el tango salió a la luz en los conventillos, otros sostienen que nació en los prostibulos. De cualquier modo, parecería innegable que el tango surgió de la convivencia de hombres de distintos orígenes, distintas experiencias y costumbres que forma-

2 José Gobello: Breve historia crítica del tango, Corregidor, Buenos Aires, 1999, pág. 19. 
ron la población heterogénea de Buenos Aires de mediados del siglo XIX, ya sea de su convivencia en los conventillos donde encontraron un lugar donde vivir, o bien en los prostibulos, donde se reunieron en busca de despreocupada diversión.

A finales del siglo XIX y principios del XX comienzan surgir letras anónimas, de temas y lenguajes groseros que se difundían en los ambientes cerrados del prostíbulo o del conventillo. Eran improvisaciones espontáneas y picarescas que cambiaron sus letras por otras más decentes al salir del círculo cerrado en el que nacieron.

Unas de las primeras letrillas de tango conocidas tratan de temas del conventillo (Señora casera) y del prostíbulo (El queco, Dama la lata). En estas letras se muestran personajes de estos ambientes como también algunas características particulares de estos.

También a esta época surgen autores conocidos que escriben letras de tango, el más representativo es Ángel Villoldo, cuyas letras de tango eran españolas por su forma (cuplé) y lupanarias en su fondo (temas ligados al conventillo o al prostíbulo). En estas letras utilizó el lunfardo y también algunas expresiones gauchescas. A esta etapa del tango se la suele llamar tango jactancioso o fachendoso, pues están compuestas en primera persona: habla un compadrito $^{3}$ o una mujer que se jactan de ser los mejores bailarines, amantes, jugadores de juegos del azar, o bien, explotadores de mujeres. Estas letras comienzan con la fórmula "yo soy", son picarescas y alegres:

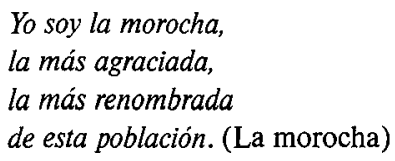

Yo soy la morocha,

la más agraciada,

la más renombrada

de esta población. (La morocha)

Luego de esta etapa alegre del tango, de fondo lupanario, surgen las creaciones que caracterizan la etapa llamada del tango-canción o tango sentimental que comienza aproximadamente a partir de 1910. Esta etapa se caracteriza por un cambio en la sociedad argentina, por la llegada masiva de inmigrantes. Las letras de tango emprenden el camino del sentimentalismo, se refleja el perfil sentimental de los compadritos. El autor representante del nacimiento de este tango sentimental es Pascual Contursi. Dos de sus letras de tango muestran sentimientos que anteriormente se ocultaban: el dolor existencial y el amor y la tristeza del abandono:

\author{
Y por eso es que en la cara \\ llevo eterna la alegría, \\ pero dentro de mi pecho \\ llevo escondido un dolor. (Matasano, 1914 ${ }^{4}$ )
}

3 "Compadrito se llamaba al joven de condición social modesta que habitaba en las orillas, es decir, en las orillas de la ciudad". Asi define al compadrito José Gobello (Ibid., pág. 13). También se le llamaba asi al gaucho que vino a la ciudad y mantuvo su vestimenta y comportamiento, su actitud independiente intacta.

4 Es interesante que la letra comienza con la fórmula "yo soy" y el protagonista se jacta de su talento como bailarin, audaz y valiente. En la segunda y tercera estrofa se descubre el dolor del compadrito, un dolor que como marca del destino lo acompaña desde sus origenes. 


\author{
Percanta que me amuraste \\ en lo mejor de mi vida, \\ dejándome el alma herida \\ y espina en el corazón. (Mi noche triste, 1915)
}

A partir de esta época las letras de tango comienzan a tratar los temas que asimismo se tratan en la literatura universal: el amor, la pena de amor, la fugacidad de las cosas humanas, la soledad, etc.

\title{
3.2. Características internas y externas de las letras de tango
}

Por su estructura externa, las letras de tango obligan a una síntesis extrema del asunto que en ellas se trata. Los textos poseen entre tres a cuatro estrofas, algunas veces el estribillo se repite. En la primera estrofa se expone, cuenta o evoca; en la segunda, más corta y de versos más cortos, se reflexiona, convoca o exorta.

Generalmente el verso es de seis u ocho sílabas, y las rimas tienen distintos esquemas según las estrofas donde se encuentran.

El tango acude a todas las formas literarias cuando plantea un tema: lírica, narrativa, dramática, epistolar, etc. Los tangos narrativos y los descriptivos son más frecuentes que los líricos. Son frecuentes también los retratos de personas o caracteres, biografias reducidas mayormente dramáticas a las que siguen advertencias o consejos para el futuro. También los autorretratos, muy frecuentes en los comienzos de las letras de tango, son una biografía si bien el eje de estas letras es la jactancia de los personajes y poseen en general una nota más humorística o irónica. Cualquiera de las formas puede incluir apóstrofe (un consejo, una confesión).

El tango también se sirve de las figuras literarias que embellecen el texto o lo esclarecen e ilustran: metáforas, comparaciones, alegorías, personificaciones, preguntas retóricas. Todas estas figuras son más o menos poéticas, algunas veces están fuertemente ligadas al ámbito rioplatense y son, entonces, bastante más dificiles de comprender sin una referencia concreta:

En el naipe de la vida, cuando cartas son mujeres, aunque lleve bien fajadas pal amor las $33 ; \ldots$ (Barajando) ${ }^{5}$

Tal vez una de las caracteristicas más interesantes del tango sea su lenguaje, un lenguaje alejado de casticismos y "españolismos", un lenguaje más cercano al habla corriente, popular, a las expresiones usuales del habla del Río de la Plata. Encontramos en las letras de tango voces gauchescas, pero es el lunfardo, el lenguaje proveniente de la jerga delictiva, el que merece la mayor atención sobre este aspecto lingüistico de las letras de tango. Este lenguaje, muestra de la influencia de la inmigración en el Río de la Plata, se utilizó en el tango con mucha frecuencia. En el lunfardo influyeron sobre todo los ligurismos del italiano y la germanía y el caló del español. También algunos términos del argot francés (ligados semántica-

5 En este ejemplo se trata de una alegoria, donde se eslabonan elementos de la realidad (la jerga del juego de cartas, el truco) para hablar de otro diferente (de las mujeres y el amor). 
mente al campo erótico), del inglés (escritos según la pronunciación española) y del portugués. Pareciera que en un principio el lunfardo fue un detalle de provocación o caricatura, pues se utilizaba frecuentemente en las letrillas picarescas de los primeros tiempos. Luego encontramos letras de tango que poseen muchos términos lunfardos aunque bien el tema y el tono sea serio ${ }^{6}$.

La escritura se pliega al lenguaje corriente, a la pronunciación rioplatense. En las letras las elles pasan a ser yes, se oscila entre las formas verbales correctas e incorrectas (fuiste fuistes), la -d final desaparece (maldá), se utiliza muchas veces la forma apocopada pa'. En cuanto al tratamiento hay una oscilación entre el tuteo y el voceo más popular en el Río de la Plata.

\section{Los temas y los motivos}

Los temas y los motivos se han ido repitiendo en el tango a lo largo de la historia. El tema es una unidad de interés - un personaje, un acontecimiento, una conducta, etc.- que puede plantearse de maneras muy diversas; los motivos son hechos, situaciones que se reiteran con variantes pero que no influyen cambiando la estructura general de un autor, una literatura o en escala universal ${ }^{7}$. Los temas pueden muchas veces aparecer como motivos y estos, pueden muchas veces ser temas en una letra de tango. Hay motivos o temas que muchas veces podemos insertarlos en una categoria de sub-temas, pues están ligados indirectamente a un tema más general y sin embargo no son sólo motivos, sino que admiten otras y muy diversas variantes. Lo cierto es que, en la delimitación de ambos, la caracteristica principal es la reiteración en alguno de los dos roles.

El tema del amor es, en el tango, el tema (y también el motivo) más difundido. Tal como en la literatura universal, el tango no dedica muchas letras al amor feliz, sino que es el fracaso amoroso la fuente de inspiración general. Hay pocas letras de tango que poseen como tema el amor feliz actual, en la mayoría de los casos el amor feliz es un motivo con una función exclusiva: se trata de un amor feliz pasado que se contrasta con el presente de fracaso, soledad y sufrimiento. Las letras que enteramente tratan el amor feliz son más poéticas, llenas de metáforas y de comparaciones, y están generalmente escritas sin términos lunfardos (el lunfardo entonces, es de suponer, se pliega al tema tratado).

El fracaso amoroso está ligado principalmente a dos subtemas que dependen o derivan de la relación amorosa: el abandono y la traición. En el abandono generalmente un hombre se queda solo, su amada (raramente el amado) se va. Se cuenta la experiencia o el sufrimiento actual del abandonado, a veces también la causa del abandono. La traición es una de las causas más comunes del abandono: él o ella se van con un tercero. Las variantes de estos motivos o sub-temas se dan de acuerdo a la reacción del abandonado, la forma de encarar la traición o el abandono. Muchas veces se aprovecha para hablar de las mujeres en general, de

6 En el lunfardo mismo se utilizan figuras literarias para mayor expresividad, muy frecuente es la utilización del vesrre o metátesis, que consiste en la inversión de las sílabas de una palabra (gotán - tango)

7 La definición es de Idea Vilariño en Letras de tango: formas, temas y motivos, Schapire,Buenos Aires, 1965, pág. 130. 
advertir a un oyente sobre la naturaleza femenina, pues en general, es la mujer la que abandona. Entre las reacciones más frecuentes de una traición encontramos la venganza y el duelo criollo que pasan a ser temas o motivos en las letras de tango. La venganza puede ser un castigo ejemplar o una cuestión de honor, mayormente se habla de una reacción emocional no controlada, los sentimientos son su móvil. En estas letras hay advertencias, odio, rencor; en algunos casos la venganza se concreta (el traicionado mata a su rival o a su examante), pero en otros no se concreta, lo impide un tercero o el traicionado se domina:

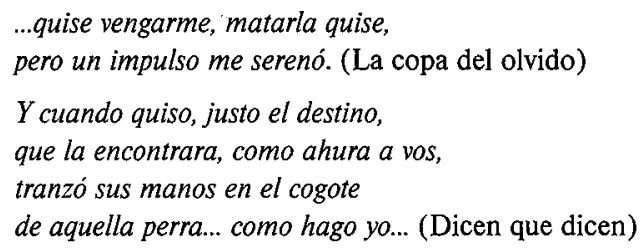

En el duelo criollo los sentimientos espontáneos no cuentan tanto como en la venganza, el duelo es una cuestión de honor, es una consecuencia lógica en el código de la hombría que no permite el engaño y la traición, por ello muchas veces se habla del duelo en términos justicieros. El duelo criollo raramente es un tema; como motivo se encadenan a él otros motivos que varian en cada letra (ya sea las reacciones del vengador o del vengado, las consecuencias del duelo - la prisión, por ejemplo, etc.). Es característico para estas letras la descripción de los elementos del duelo: el cuchillo, la daga o la faca, y consecuentemente la herida o la marca.

Luego de un abandono está evidenciada en la letras de tango la posibilidad del reencuentro de los ex-amantes. El reencuentro puede ser casual o provocado, pero salvo excepciones, es siempre decepcionante. En general suceden dos cosas: ella está envejecida, deshecha, o ella pasa bonita, adinerada y elegante:

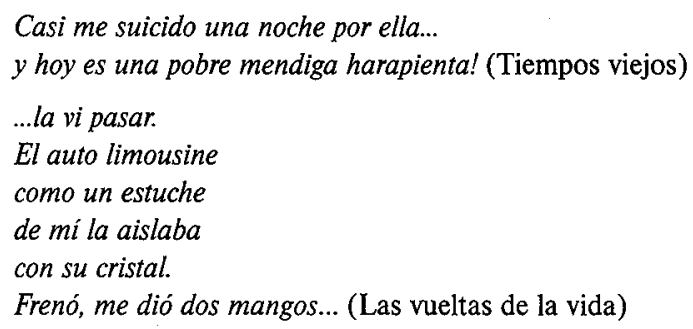

Otra forma de reencuentro es cuando el que abandonó regresa. Generalmente regresa la mujer arrepentida, buscando lo que abandonó. La letra se centra en cómo la recibe el hombre, que actitud adopta frente al regreso inesperado. Mayormente el hombre la recibe y le perdona su abandono, en pocos casos la despide. Un motivo o tema más excepcional es de la persona que está por irse, la ida. En estas letras se cuenta desde la perspectiva del que concretará el abandono, se cuentan las causas (pobreza, ambición, hastío, otro amor, etc.).

La mujer fatal es un tema o un motivo en las letras de tango. Como motivo se relaciona al abandono y la traición, al tema de la madre. Frecuentemente la mujer es causa de abandono para el hombre, que no sólo abandona a una mujer, muchas veces a su propia madre o 
a su familia. La mujer fatal es causa de vicios y de corrupción de la vida decente de un hombre, la sensualidad y belleza atraen al hombre y terminan deshaciendo su vida.

El alcohol es uno de los motivos primordiales en el tema del amor. Salvo excepciones la embriagadez es siempre un caso de amor desdichado: el abandono o la traición son excusas perfectas para beber. Generalmente es el hombre el que bebe, pocas veces una mujer, a veces la pareja. Se bebe principalmente para olvidar, para ahogar un dolor, es una cuestión de evasión que a veces no se cumple:

\title{
Mozo! Traiga otra copa \\ y sirvase de algo que quiera tomar.. \\ Quiero alegrarme con este vino \\ a ver si el vino me hace olvidar (La copa del olvido)
}

Por lo general el borracho habla a un camarero o bebe en grupo, otras veces la letra no es otra cosa que el soliloquio del borracho abandonado y sus reflexiones.

Tanto el alcohol como el tango, las drogas y el cabaret son detalles en la descripción de la mala vida, son motivos que se insertan en otros motivos y temas.

El tema de la madre es, después del tema del amor, el tema más tratado en las letras de tango. Con él se relacionan los sub-temas del hijo y de la hija ingrata que abandonan a su madre. El tema de la madre está muchas veces relacionado con el paso del tiempo y el regreso al barrio natal. El hijo ingrato generalmente abandona a su madre por otra mujer (la mujer fatal que es, en cuestión moral, la oposición de la madre) o por otras causas: amigos, juventud, ambición. La madre queda desamparada, sufriendo por el abandono (que siempre es más cruel que otro tipo de abandono), pero es usual que el hijo regrese a su lado arrepentido o bien, al final de todo, evoque a la santa madre que siempre termina perdonando. Excepcionalmente el hijo no se arrepiente, entonces la letra está llena de reproches y advertencias al hijo desalmado. El amor materno es siempre incondicional, puro, un valor moral intachable; la madre es la mujer ejemplar en el tango, la que consuela y protege a sus hijos; aunque abandonada, desamparada, su amor se muestra siempre puro y fuerte hacia ellos:

\author{
...bajó del cielo \\ la mujer que más queria yo: \\ es mi madre que trae el consuelo \\ la que nunca mi mente olvidó (¿Por dónde andará?)
}

La hija siempre abandona a su madre por un hombre o por ambición. Este motivo está fuertemente relacionado con otros temas y motivos: la mujer que se corrompe en la mala vida, el tango y sus efectos, la mujer que triunfa en la mala vida, el paso del tiempo, etc. Sucede con la hija algo parecido que con el hijo: regresa, se arrepiente; es también una excepción que no lo haga. Por supuesto la madre siempre termina perdonando.

Raramente se hable mal de los padres, si excepcionalmente sucede, los padres que no poseen las características generales, son siempre los ajenos:

Hoy me entero que tu mama,

noble viuda de un guerrero,

es la chorra de más fama (...)

$Y$ he sabido que el guerrero (...) 
Hemos visto que la mujer fatal es la causa de la perdición de un hombre decente, puede ser también la culpable de sufrimientos y penas o la hija ingrata que abandona a su pobre madre, en fin, la mujer de carácter dudoso es, en el tango, un tema o motivo que se reitera, es generalmente la causa de los sufrimientos en el tango. Esta mujer posee siempre características comunes (belleza, sensualidad, etc.), varía solamente el punto de vista, quién es el centro de atención en las letras de tango (de aquí si es un tema o un motivo). Cuando se habla de ella misma, de la causa de su perdición, hablamos del tema de la mujer de la mala vida o de la que se pierde. Este tema está asimismo relacionado con el tema del paso del tiempo, del tango y sus efectos, y como habíamos mencionado, con el tema de la madre y el motivo de la mujer fatal.

La que se pierde sin embargo cumple con una característica especial: su origen es siempre honrado y humilde. Según la causa de su perdición se diferencian dos tipos de mujeres: la inocente engañada y la que, voluntariamente, se ha dejado a la vida de placeres y perdición.

La inocente engañada es la bella, honrada y humilde mujer que engañada con promesas de amor termina en la vida nocturna, en el cabaret (algunas veces también el tango influye en su perdición). En estas letras predominan los sentimientos de nostalgia por el pasado puro y honrado, el recuerdo de los padres, el arrepentimiento, el deseo del regreso, la tristeza y la soledad. Generalmente el tango está relatado por un testigo, una tercera persona que puede ser testigo del trágico final de la vida de esta mujer, o bien, testigo del presente desdichado de la inocente engañada que predice un final desgraciado de miseria, soledad y vejez:

$$
\begin{aligned}
& \text { Yo sé que hasta el alma dieras } \\
& \text { por volver a lo que eras... } \\
& \text { No podrás: la primavera } \\
& \text { de tu vida ya se fue... (Mano cruel) }
\end{aligned}
$$

Pero no siempre la mujer termina en la mala vida por un engaño, hay otras que lo hacen por voluntad propia, su 'mal paso' es voluntario y premeditado. La que huye de la honradez y humildad de su barrio y de sus padres buscando el lujo y el placer (a veces hay algún hombre que la seduce con promesas de amor y lujos, pero que en realidad solo precipita la decisión de la mujer) es la mujer que busca la mala vida:

\author{
...vos rodaste por tu culpa \\ y no fue inocentemente \\ -berretines de bacana \\ que tenías en la mente (Margot)
}

También es un testigo, generalmente, el que narra. Mayormente hay remordimientos y arrepentimientos, deseos de volver a los orígenes humildes y honrados, soledad y vejez, pocas veces las mujeres no se arrepienten del mal paso, salvo cuando se cuenta el presente exitoso de la mujer. Sin embargo predominan las advertencias, los reproches y sobre todo, las predicciones de una muerte temprana y miserable: 
El tango es un tema o un motivo cuando se le canta a su danza, a su música, a sus letras, a sus características o a su influencia y función en la vida de distintos personajes. Se diferencian un punto de vista positivo (frecuentemente relacionado con los tangos jactanciosos) y otro negativo (sobre todo cuando el tango es un motivo) al hablar del tango. A veces el tango habla en primera persona, otras se lo describe o define.

Las características más difundidas sobre el tango son la tristeza, el dolor, una agonía; a veces es llanto y quejas, otras sensualidad y sentimientos, o compañero y amigo, y muchas veces también perdición: se le reprochan infinidades de cosas.

El tema o motivo del tango se relaciona con los ambientes del tango, con el tema de la mujer perdida, con el paso de los años, etc.

El paso del tiempo es, en la literatura universal y también en el tango, uno de los temas (y motivos) más tratados. El paso del tiempo es sobre todo un motivo, en cualquier caso, encadena un sinfin de variaciones. Como motivo se relaciona sobre todo a las personas y a los lugares.

Al hablar de la mujer en el tango (de la hija ingrata que abandona a su madre, de la que abandona o traiciona a su amado, de la mujer fatal que atrapa en sus redes lujuriosas a un hombre honrado) aparece muchas veces el motivo del paso del tiempo, ya sea en las advertencias o en las criticas (se muestra una característica didáctica que posee el tango), otras veces en consejos afectuosos con simpatía y compasión. Se trata siempre de un testigo o del presente exitoso de la mujer o del final triste de la misma, lo importante es dejar siempre en claro que el tiempo pasa y que las cosas humanas son pasajeras, que la vejez es un hecho (mayormente son advertencias negativas, que presagian un final de decadencia):

\section{Comprendé que la vida se va \\ $Y$ se acaban los brillos y el rango... \\ Cuando el llanto te venga a buscar \\ Acordate, muñeca, de mí... (Muñeca brava)}

Algo parecido sucede con el hombre en el tango y el paso del tiempo: el hombre que triunfa en el arrabal, en el cabaret, en los salones de baile obtiene triufos no son sólo materiales sino principalmente de renombre, fama, amores, etc. También en estas letras hay mayormente un testigo que relata; la manera de encarar la vida del hombre es también similar a la perspectiva que se adopta para hablar de la mujer: se habla de su carrera o su vida hasta el final negativo (como una biografia reducida), o bien se expone el presente de éxito advirtiendo, presagiando el final negativo que le espera. El paso del tiempo se refleja sobre todo de acuerdo a las vueltas de la vida, de la suerte, no tanto el paso de los años, como sucedía con la mujer. A veces es el mismo personaje quien compara su pasado brillante y exitoso y el presente miserable que padece: 
Pero algo vos darias por ser solo un ratito

El mismo compadrito del tiempo que se fue,

Pues cansa tanta gloria y un poco triste y viejo

Te ves en el espejo del viejo cabaret. (Bailarin compadrito)

El motivo de la vuelta sirve más que nada para expresar idea de fugacidad: entre la ida y la vuelta el tiempo se ha encargado de cambiar, destruir o arruinar lo que se había dejado. Este motivo, asimismo, se relaciona con otros: se vuelve al amor maternal, se vuelve a un lugar (el barrio, a una calle, a un café) donde se fue feliz, el lugar de la juventud, de los amigos o de un amor. Los lugares pueden ser motivos o temas por si solos (por ejemplo la calle Corrientes, Buenos Aires) cuando se los evoca o describe, pero relacionados con el motivo de la vuelta muestran algunas características particulares: el lugar al que se vuelve pudo o no cambiar por el paso del tiempo, mientras que el protagonista casi siempre sufrió los cambios relacionados con el tiempo y regresa viejo, deshecho, vencido.

El paso del tiempo se expresa en las letras de tango más que nada como un motivo, raramente es un tema que se trata en una letra entera, algunas veces es posible que se exprese esta idea de una manera más autónoma, frecuentemente en algunos versos. Muchas veces se destaca la idea de deseo de regresar al tiempo pasado, a la juventud (que es en el tango sinónimo de felicidad). En muchas letras se reflexiona sobre el paso del tiempo, sobre la vejez, sobre la angustia que causa perder todo un mundo bello e inocente del pasado, sobre la inminencia de la muerte.

En las letras de tango hay muchos otros temas y motivos (las carreras, Gardel, el carnaval, etc.) cuyo análisis es imposible en este artículo. Hay, sin embargo, una categoría de letras de tango que tratan hechos que se relacionen de una manera más directa a la realidad histórica y social de la Argentina; entre estos se destacan los tangos de protesta o de crítica social, que reflejan problemas que se vivieron en el pais en distintas épocas. La desocupación, la miseria, la crisis económica del ' 30 , la decadencia moral y el espíritu materialista y tramposo del siglo XX son todos temas que se tratan en estas letras siempre desde un punto de vista negativo. Por último, y entre los tangos que hablan de una realidad más palpable, se encuentran los tangos que tratan el tema de la inmigración y los motivos que a ella se relacionan: la nostalgia por el pais lejano, por un amor perdido; la soledad del inmigrante y el alcohol que permite olvidar o soportar la nostalgia.

\section{Conclusión}

Las letras de tango descubren al oyente o lector un plano no tan conocido del tango. Su origen y su evolución son interesantes e importantes al hablar de los temas y motivos, tal vez también para conocer el porqué de la mitología a la que está sujeto el tango, los símbolos que mundialmente y de forma general quedaron ligados al tango.

Los temas y los motivos en el tango son clasificables, aunque la clasificación puede hacerse de maneras muy diferentes, desde distintos puntos de vista. Muchas veces es dificil definir un tema o un motivo, pues adoptan distintas características en las letras de tango. En general se destacan tres tendencias: la tendencia moralizadora de las letras, la de los consejos o advertencias, otra tendencia de denuncia o queja de la vida moderna, y otra más sentimen- 
tal, donde se cuentan experiencias y sentimientos. Pero es innegable que las letras de tango reflejan una realidad, la rioplatense, en un tiempo determinado: no importa el punto de vista utilizado, tampoco el tema o motivo tratado, las letras se encargan de comunicar algunas características que han quedado testimoniadas en ellas. El tango es, por lo tanto, un género realista y popular en cuanto a sus temas, en cuanto a su fondo y su lenguaje.

El análisis global de las letras de tango nos muestra que es la expresión más original del Río de la Plata, un género pintoresco que encierra en sí mismo un trozo de vida y de historia, sentimientos y experiencias que se convierten en universales al salir de su círculo tanguero.

\section{Bibliografia citada y consultada}

AMUCHÁSTEGUI, Irene: El día que el tango tuvo nombre (www.clarin.com.ar/diario/97-09-28/c-00811d.htm)

BoRgEs, Jorge Luis: Evaristo Carriego, Obras completas (1923-1949), Ed. Emecé, Buenos Aires, 1989.

Díez BoRQue, José María: Comentario de textos literarios, Ed, Playor, Madrid, 1998.

GoBello, José: Letras de tangos, Ed. Nuevo Siglo, Buenos Aires, 1995.

GoBello, José: Breve historia crítica del tango, Ed. Corregidor, Buenos Aires, 1999.

GoBello, José: Nuevo diccionario lunfardo, Ed. Corregidor, Buenos Aires, 1998.

GUERRA, Hilda: El tango vuelve a tener quien lo escriba (www.clarin.com.ar/diario/99-10-02/c-01201d.htm)

Ley de tango (www.tangou.com.ar/leytango.htm)

NAVARRo, José Antonio: La historia del tango (www.geocities.com/Paris/Bistro/4011/tango)

PENAS, Alberto: Recopilación antológica para una sociologia tanguera, Ed. Corregidor, Buenos Aires, 1998.

SALAS, Horacio: El tango, una guia definitiva (www.ocf.berkeley.edu/ fmb/gotan.html)

SALAS, Horacio: El tango: seña de identidad de lo argentino (www.literatura.org/Proa/Proa_Salas.html)

Tangueando (testimonios, cuentos y relatos); selección, prólogo y notas pedro Orgambide, Ed. Antártica,

Buenos Aires, 1992.

Teorias sobre el origen del tango (www.clarin.con.ar/diario/97-09-28/c-00906d.htm)

VIDART, Daniel: El tango y su mundo, Ed. Tauro, Montevideo, 1967.

VILARINo, Idea: El tango, Ed. Cal y Canto, Montevideo, 1995.

VILARIÑo, Idea: Las letras de tango: forma, temas y motivos, Ed. Schapire, Buenos Aires, 1965. 


\section{TANGO: TEME IN MOTIVI}

Argentinski tango je zvrst glasbe in plesa, ki razkriva poslušalcu ali bralcu besedil paleto čustev, običajev in predvsem izročilo prebivalcev glavnega mesta Argentine. V članku, ki obravnava le del vseh možnih tem in motivov, se razkriva najbolj neznana stran argentinskega tanga - tj. besedil. Besedila tanga kažejo način mišljenja in čustvovanja prebivalcev Buenos Airesa ter postopoma razkrivajo del zgodovine in različne poglede. Liki in prostori, povezani s tangom, so sčasoma zaznamovali mitologijo tanga.

Razvrstitev tem in motivov, ki se $v$ tangu ponavljajo, je možna na več načinov. Nekatere teme in motivi so znani iz svetovne literature, npr. neizpolnjena ljubezen ali minljivost časa, druge pa so vezane na ambient tanga in so izven konteksta ter zgodovine samega tanga nerazumljive. Teme in motivi prikazujejo tudi nekatere moralne vrednote, značilne za prebivalce Argentine, med njimi so tudi takšni, ki so neločljivo povezani s tangom: ženska, ki se prepusti nočnemu življenju in čarom tanga, moški, ki zapusti materino ljubezen zaradi bordela ali tanga samega, mati, ki s svojo brezpogojno ljubeznijo trpi blodnje svojih otrok, osebe, ki se vračajo domov in iščejo izgubljene ljubezni ali prijateljstva. Besedila ne predstavljajo na poseben način samo oseb, temveč tudi kraje oz. ambiente tanga, ki čutijo in se spreminjajo tako kot posameznik. Tem in motivov je $\mathrm{v}$ besedilih veliko, njihova celotna analiza je skoraj nemogoča, zato članek predstavlja na splošno le najbolj značilne in pomembne.

Besedila tanga vsebujejo ljudsko izročilo, ki ga prepoznamo iz analize notranje zgradbe - zlasti žargonskega lunfarda, ter iz same zgodovine nastanka zvrsti. Tango je fascinantna in neizčrpna zvrst glasbe, kjer se prepletata stvarnost in notranja podoba prebivalcev Ría de la Plate. 